\title{
Teacher Leadership Begins with Self-Leadership
}

\section{Louis Langdon Warren}

Department of Elementary and Middle Grades Education, East Carolina University, Greenville, North Carolina, USA

\section{Email address:}

warrenlo@ecu.edu

\section{To cite this article:}

Louis Langdon Warren. Teacher Leadership Begins with Self-Leadership. Teacher Education and Curriculum Studies. Vol. 6, No. 1, 2021, pp. 1-4. doi: 10.11648/j.tecs.20210601.11

Received: October 22, 2020; Accepted: December 15, 2020; Published: January 12, 2021

\begin{abstract}
This study examines teacher leadership and how it starts with self-leadership. An effective teacher leader must be able to lead oneself effectively before he or she can lead others within and outside the classroom. Self-leadership is the practice in which one intentionally influences their thinking, feelings, and actions in order to achieve specific objectives. Selfleadership is an aspect of positive self-influence by defining how one excels within the teaching profession and within the classroom. Self-discovery is a vital step to effective self-leadership. Self-discovery is initiated by self-reflection, which comprises examining individual life, experiences, and responses to situations. Self-discovery is a critical process not only for teacher leadership, but also personal development, performance improvements, and ultimate life enrichment. Self-leadership is founded on self-acceptance. Self-leadership is about one choosing to influence their thinking, feelings, and actions intentionally. Teacher leadership often starts with good self-leadership such that a teacher may be able to influence the learners positively.
\end{abstract}

Keywords: Self-leadership, Teacher Leadership, Students, Achievement

\section{Introduction}

Leadership entails an individual or organization's ability to guide others towards achieving a common objective [10]. As such, the leader ought to have a clear vision of the individuals or the institution they guide. Often, leaders are the masterminds of the due process; hence the teams or the individual generally sees as much as is revealed by the leader. A good leader should comprise some key attributes such as self-discovery or self-mastery and the mastery of the due process. Teachers are in charge of the professional development of their students. They shape the attitude and skill set of their learners for a successful career in their respective disciplines. Teacher's self-leadership is a critical determinant of the students' learning process since teachers manifest thoughts based on the conception of their world. As such, self-leadership is a core ingredient in effective teacher leadership.

Effective teacher leadership has substantial impacts on the students' achievements. The teacher's perspective on education and professional development not only change the school climate but also plays a critical role in meeting the needs of the learners [6]. Teacher leadership entails modeling appropriate instruction, assembling learning resources, establishing professional collaboration, and advocacy. Cheung et al. denoted that teacher self-leadership shapes how they deliver values, skills, and expertise to their students [4]. This study examines the stance that teacher leadership starts with self-leadership. The approach of the study is that strong self-leadership is a core ingredient to effective teacherleadership. Other vital concepts evaluated in the study comprise self-leadership, self-discovery, the beliefs and values that make us, and self-acceptance in the context of teacher-leadership.

\section{Self-Leadership}

Self-leadership is about the practice in which one intentionally influences their thinking, feelings, and actions in a bid to achieve specific objectives. Among the critical significance of efficient self-leadership is becoming a more efficient and effective leader, from inside-out. For an excellent self-leadership, one ought to have an outstanding vision of the objectives at hand to reposition themselves to the tasks involved [13]. Self-leadership, from a different perspective, is the aspect of positive self-influence. Among the individuals whose self-leadership is of the essence are the 
leaders, among whom are the teachers. In essence, selfleadership is essential in defining how one excels through uncertain, complex, and volatile circumstances.

The teaching profession is about changing the attitude and instilling knowledge in learners; hence a teacher ought to be able to change their attitudes and learn new approaches by themselves. An individual who cannot influence their attitudes and learn new skills do not qualify to instill discipline, skills, and change attitudes of learners. Teachers, as such, need self-leadership to acquire justification to impart knowledge and discipline to students.

The teachers' outcome in the teaching profession results from their views towards the education profession [11]. With complimentary views and attitudes towards education are more likely to impart more skills to the learners. While teachers in the same discipline handle the same academic content, some teachers might be more effective in delivering the content to the learners. The basis for differences from one teacher to another in delivering the same content is the personal views or attitude towards education. A critical component of self-leadership is deciding, expressing, and experiencing oneself, which characterize teachers' career practice. How teachers mold their worldviews and personality directly impacts their career expression and, ultimately, the students they teach.

\section{Self-Discovery}

Self-discovery is a vital step to effective leadership. The process of self-discovery entails individuals to develop a better understanding of their weaknesses and strengths. The habit of self-reflection enables one to dive deeper into one's inner world and the subconscious mind [9]. In essence, no other persons in the world feel, think, and experience life as the other. Self-reflection is the roadmap to self-discovery, from which one discovers unique attributes, skills, and perspectives that aid them in the leadership roles. Leadership, especially in a teacher's capacity, is about human chemistry, from which one develops self-awareness, view the outward world, and build a new community from the classroom setting [8].

The ever-busy life activities often undermine the ability of individuals to self-reflect, thereby losing sight of themselves. A significant impediment to progressive leadership development is the failure to regularly self-reflect. The undermined process of self-discovery subsequently undermines effective leadership development. Often, teachers tend to get too busy with daily work, such that they fail to self-discovery, and ultimately lose their best self. A leader who fails to self-reflect eventually becomes more deficient in leadership, as they do not discover the ever-evolving personality and circumstances at the workplace. Leadership is generally a self-discovery journey, where one ought to learn and a re-learn.

As a process, self-discovery entails four segments; selfawareness, interest awareness, hopes, and dreams, as well as career discovery [15]. While self-awareness is about developing an understanding of personal characters, interest awareness is related to establishing personal interests. Hopes and dreams are about defining individual plans and expectations for the future, while career discovery is about determining a profession that suits the individual personality. However, self-discovery is initiated by self-reflection, which comprises examining individual life, experiences, and responses to situations. Self-discovery is a critical process not only for teacher leadership, but also personal development, performance improvements, and ultimate life enrichment.

\section{Beliefs and Values That Make Us in Leadership}

Personal values and beliefs have a direct influence on one's quality of work and interpersonal relationships. Among the fundamental values that may have direct impacts on individual leadership includes honesty, perseverance, loyalty, and environmental issues, among others. Besides, culture has a significant influence on individual values and relationships and subsequent leadership quality. Generally, culture defines how individuals view the world. As such, culture can influence personal attitudes, values, and approaches to issues and hence leadership quality. Successful leadership development requires one to discover positive values and beliefs that enable the appropriate leadership traits.

Influential leaders are the ones that keenly identify positive values and implement them in their daily life in career practice [1]. Leadership roles entail making the most appropriate decisions or enabling others to work towards a standard or specific goal. Individuals who know their positive core values are most likely to motivate others by imparting the same synergy. Leaders usually walk along with the people they lead to achieve the expected objectives. As such, identifying values and beliefs that suit the expected activities to achieving the objectives is a vital ingredient to success.

Leaders and potential leaders ought to work on acquiring values and traits that shape them for leadership roles. Leadership requires specific traits and values, some of which may be learned, while others are inherent. Leadership can be learned by dedicating self to acquiring essential attributes to good leadership. For example, an effective leader should motivate others but not agony, flexible, wisdom, integrity, courageous, respect, and humility, among others. Besides, self-awareness, visionary, and good communication skills are critical personal traits in shaping leadership [1]. An individual can learn how to be results-oriented, reliable, and empathetic. A teacher can endeavor to acquire positive values and attributes that suit their careers such that they are more useful to the learners. While learning institutions impart professional skills for teaching, teachers have an individual responsibility to shape themselves for the task-by acquiring fundamental values and traits to suit their professions. 


\section{Self-Acceptance}

Effective leadership is founded on self-acceptance. Upon developing sufficient self-awareness, one ought to accept their weaknesses and strengths without any elements of selfdenial. On the other hand, one has to accept things beyond their control while working on improving things within their control [2]. To lead others effectively, they need to appreciate the good things about their situations while getting in peace with the bad ones. Love for oneself is one step to good leadership. Teachers have a much bigger responsibility in molding themselves to fit in the new education world order with the ever-evolving teaching profession. Among some key aspects that fit the leadership role are acknowledging the need for consistency learning new things and approaches, believing in oneself, and celebrating wins.

Individuals that always focus on the negative things about themselves are not likely to be effective leaders. Focusing on ones negative aspects has adverse effects on self-esteem, which undermines personal abilities to influence others. Great leaders are influencers since they influence attitudes, instill discipline, motivate, instill knowledge, and serve as a role model [14]. Concentration on the negative aspects enhances negative influence on oneself and subsequent abilities to lead others. It is Imminent that people often tend to focus on the negative aspects; however, their influence should be steered to bring about self-improvement. Selfawareness about the negative aspects should be used as a steppingstone to a better self instead of undermining the positive aspects.

Another critical element about self-acceptance is the ability to take ultimate control of feelings and actions. Individuals with complete self-awareness are better placed to take necessary action to become great leaders. This is unlike poor leaders who often fail to take action to enhance their leadership capabilities. Besides, leadership roles are closely associated with negative feelings or emotions, especially in poor performance. Influential leaders are the ones who take such instances of failure as life lessons and package themselves for better performance [12]. Effective leadership is about taking ultimate control of personal emotions and actions such that they do not get the way of their leadership roles.

Mostly, people fail to identify their strengths, which is a vital process to self-acceptance. Acknowledging personal strengths is an aspect that could positively impact individual leadership performance. While at times, it is not easy to overcome personal weaknesses, capitalizing on personal strengths could be all that one can do to take on leadership tasks [3] effectively. An honest evaluation of personal strengths improves not only self-esteem, but also synergy to take on the daily challenges associated with leadership. Leveraging on personal strengths could also help cover up personal weaknesses in the leadership positions.

Self-acceptance is of the essence in overcoming obstacles in life challenges. Self-acceptance helps one identify themselves with things they can perform well and those they may not perform well. As such, leaders with self-acceptance avoid disappointment by not engaging in tasks that are not likely to attain expected performance. Self-acceptance for a leader implies that one may seek to collaborate with capable individuals on areas of weakness while taking charge of things within their means. Generally, effective leaders are performers who not only live to the dream of their teams but also enable their followers to have a clear vision of their future [7]. As such, self-acceptance is of the essence in enabling leaders to achieve growth and success less strenuously.

Self-acceptance is a recipe for good health. When individuals get at peace with their situations, they positively impact the physical, mental, and emotional health. Self-love helps one avoid self-comparison and improve confidence in addressing leadership challenges [5]. During the leadership course, there is often the case that there are people who seek to pin the leaders down by pinpointing their weaknesses. Such attempts may have dire impacts on the leaders who had not developed self-acceptance and discovery and ultimately render ineffective leaders. Self-acceptance in the context of good health entails acknowledging one is good enough to take on leadership; however, there is room for improvement.

\section{Conclusion}

Self-leadership is about one choosing to influence their thinking, feelings, and actions intentionally. Teacher leadership often starts with good self-leadership such that a teacher may be in a position to influence the learners positively. The teachers' outcome in the teaching profession is the result of their views towards the education profession. People often fail to self-discover because of a high focus on work, thereby undermining the process of leadership development. The self-discovery process is anchored on selfreflection from which one determines personal weaknesses and strengths, aspirations, and interests. Developing positive values and beliefs significantly influence effective leadership. Culture has a direct impact on personal values and beliefs and hence their leadership capability.

Upon self-reflection, self-acceptance is critical to becoming an effective leader. Self-acceptance is about appreciating the things one can do and embracing a positive attitude towards things that are beyond individual control. One ought to develop the ultimate skills to control their emotions and actions for an effective leadership role. Selfacceptance is a critical ingredient to overcoming leadership obstacles, especially hostile critics from other people, which may be a trap to downfall. Besides, self-acceptance has a direct influence on personal physical, emotional, and mental health.

\section{References}

[1] Bono, J. E., \& Judge, T. A. (2004). Personality and transformational and transactional leadership: a meta-analysis. Journal of applied psychology, 89 (5), 901. 
[2] Brown, N. W. (2009). Becoming a group leader. Merill.

[3] Bernard, M. E. (Ed.). (2014). The strength of self-acceptance: Theory, practice, and research. Springer Science \& Business Media.

[4] Cheung, R., Reinhardt, T., Stone, E., \& Little, J. W. (2018). Defining teacher leadership: A framework. Phi Delta Kappan, $100(3), 38-44$.

[5] Chamberlain, J. M., \& Haaga, D. A. (2001). Unconditional self-acceptance and psychological health. Journal of RationalEmotive and Cognitive-Behavior Therapy, 19 (3), 163-176.

[6] Helterbran, V. R. (2016). CHAPTER 12: Teacher Leadership: Overcoming" I Am Just a Teacher" Syndrome. Counterpoints, $466,114-120$.

[7] Hallinger, P. (2018). Bringing context out of the shadow. Educational Management Administration \& Leadership, 46, 5-24. doi: $10.1177 / 1741143216670652$

[8] Kaplan, R. S. (2015), What You Really Need to Lead: The Power of Thinking and Acting Like An Owner, Boston: Harvard Business Review Press.

[9] MacBean, A. (2014). Dancing into diversity: A curriculum for self-discovery, empathy, and creative leadership. Journal of Dance Education, 14 (3), 117-121.
[10] Northouse, P. G. (2019). Introduction to leadership: Concepts and practice. SAGE Publications, Incorporated.

[11] Park, H. S., \& Han, J. Y. (2015). Self-leadership, critical thinking disposition, the satisfaction of clinical practice, and clinical practice competency of nursing students. Journal of the Korean Data and Information Science Society, 26 (3), 695-706.

[12] Schneider, L. (2020). American Indian education in Idaho: Dismantling the deficit model and honoring resilience. In Jacob, M. M., Johnson, S. R., (Eds.), On Indian Ground: The Northwest (pp. 21-37). Information Age Publishing.

[13] Stewart, G. L., Courtright, S. H., \& Manz, C. C. (2011). Selfleadership: A multilevel review. Journal of Management, 37 (1), 185-222.

[14] Wang, F. (2017). Leadership as a subversive activity: Principals' perception. International Journal of Leadership in Education, 21 (5), 531-544.

[15] Watson, L. (2004). Self-leadership: Becoming an exceptional leader. Radiologic Technology, 75 (6), 457-471. 